\title{
Study of Microstructure and Corrosion Behavior of Multilayered Ni Coatings by Ultrasound-assisted Electrodeposition
}

\author{
Huawei Li ${ }^{a}$, Lingling Xing ${ }^{a, b}$ (D), Yunsong Niu ${ }^{b, *}$ (D), Shenglong Zhu ${ }^{b}$, Fuhui Wang ${ }^{c}$ \\ a Shenyang Normal University, College of Chemistry and Chemical Engineering, 110034, \\ Shenyang, China \\ ${ }^{b}$ Institute of Metal Research, Chinese Academy of Sciences, Shi-changxu Innovation Center for \\ Advanced Materials, 110016, Shenyang, China \\ ${ }^{c}$ Northeastern University, Shenyang National Laboratory for Materials Science, Corrosion and \\ Protection Division, 110819, Shenyang, China
}

Received: July 03, 2020; Revised: September 09, 2020; Accepted: October 15, 2020

\begin{abstract}
Multilayered Ni coatings were successfully deposited on martensitic stainless-steel substrates by electrodeposition method with intermittent ultrasound. It is a novel kind of multilayered microstructure of stacked-up sandwiches, whose compositions of each monolayer are the same to those of its adjacent layers. The grains of ordinary Ni layers are columnar, vertically to the substrate surface, but the grains of ultrasonic Ni layers grow parallel along the substrate surface. By multilayered structure, the pinholes running through the coating were obviously inhibited, because the multilayered Ni coating can cover the whole surface of the substrate without the direct pinhole passages down to the substrate. Therefore, its corrosion mechanism is the uniform corrosion. For the ordinary Ni coating, the direct corrosion on the substrate can occur through the pinholes, which are the convenient passages for corrosive media to reach the substrate easily. This behavior can lead to the Fe/Ni galvanic corrosion, coating adhesion reduction, and quick formation of coating cracks in the ordinary Ni coating.
\end{abstract}

Keywords: multilayered coatings, ultrasound, corrosion, pinhole.

\section{Introduction}

Electrodeposited nickel coating has wide industrial applications due to its excellent anti-wear and anti-corrosion characteristics. However, it is well known that the pinholes, which can penetrate the whole coating, can be found in the conventional Ni coating ${ }^{1}$. Hence, conventional electrodeposited Ni coating cannot be used directly as a corrosion-resistant coating unless its thickness exceeds $25 \mu \mathrm{m}^{2,3}$. At present, the desired performance criteria of electrodeposited Ni coatings are toward the high corrosion resistance and tough wear resistance ${ }^{4,5}$. Therefore, new electrodeposition technologies are urgent to meet the diversified requirements of industrial applications. Intense efforts have been made for the synthesis of the Ni coating by nano-particles ${ }^{6-8}$, as well as embedding ultrahard particles into the electrolyte, such as $\mathrm{SiC}$ and $\mathrm{Al}_{2} \mathrm{O}_{3}{ }^{9,10}$. It is well demonstrated that the modified coatings with nanocrystallines and the embedded particles showed good corrosion and wear properties ${ }^{11,12}$.

However, irrespective of the mentioned-above improvements, electrodeposited monolayer deposits still suffered from an evitable drawback - pinhole. By introducing multilayered structure, multilayered coating can interrupt the opening feature of pinholes from coating surface to substrate, and thus lower the porosity density considerably ${ }^{13}$. Moreover, monolayer Ni coating does not perform well for the normal angles due to their high internal stress ${ }^{14}$. Multilayered structure changes the stress state in the coating, which relieves interfacial stresses

*e-mail: ysniu@imr.ac.cn if the adjacent layers which develop tensile and compressive stresses are involved. In this case, the corrosion will occur at the defect site, and the flaking in large areas around the corroding site in the conventional $\mathrm{Ni}$ coating will be impeded. Past studies focused on the multilayered coatings, whose composition of any monolayer were different from that of its adjacent layers, i.e. $\mathrm{Ni} / \mathrm{Cu}^{15}, \mathrm{Cr} / \mathrm{Ni}^{16}, \mathrm{Zn}-\mathrm{Ni}^{17}$ and $\mathrm{Ni}-\mathrm{W}^{18}$ modulated coating. It has been mentioned that some multilayer coatings exhibited higher corrosion resistance than single layer ones ${ }^{19,20}$. In multilayer coatings, the corrosion resistance was increased due to the reduction in interconnecting pores and defects ${ }^{20,21}$. The anti-corrosion mechanisms are as follows: i. Corrosion initiates from the outer layer and gradually produces a short-range pinhole from surface to the sublayer; ii. As the pinhole develops to the sublayer which exposes to the corrosive solution, the corrosion process spreads here, instead of penetration toward the substrate; iii. the pinhole penetrates throughout the sublayer until the following underlayer exposes to the corrosive solution and again the cathodic protection of sublayer and the lateral propagation of corrosion in following layers proceeds ${ }^{22}$. This corrosion/protection process postpones the progress of corrosive medium to the steel substrate. Therefore, if the layer number (interfaces) is more, the corrosive medium will take a much longer time to penetrate through all those layers into the substrate ${ }^{23}$.

Nowadays, effect on high-power ultrasound in electrodeposition is an active research area. Ultrasonic 
irradiation with high intensity has exhibited both chemical and physical effects on electrochemical process, i.e. mass-transport enhancement ${ }^{24}$, surface cleaning, radical formation, instantaneous nucleation behavior ${ }^{25}$, as well as decreasing cathode polarization and increasing exchange current density ${ }^{26-29}$. In fact, the ultrasonic actions bring two important effects: cavitation and acoustic streaming. The former phenomena concern the formation, growth, and implosive collapse of bubbles in the solution which were irradiated with high-intensity ultrasound, while the latter ones relate to time-independent and unidirectional flow currents in a fluid due to the presence of ultrasonic waves ${ }^{30}$. The electrodeposited coatings, which were obtained from the ultrasound-assisted bath, indicated significant improvements in microhardness and wear resistance of the composite coatings, compared to the coatings without ultrasound ${ }^{31}$. Shetty and Chitharanjan Hegde $^{23}$ induced a kind of multilayer Ni-Co alloy coating using periodic acoustic cavitation, and found that corrosion rate was increased by reducing the ultrasonic processing time since the sonication promoted homogeneity and modulated

Table 1. Composition of the depositing solution and the depositing parameters.

\begin{tabular}{cc}
\hline $\mathrm{NiSO}_{4} \times 6 \mathrm{H}_{2} \mathrm{O}: 250 \mathrm{~g} / 1$ & Temperature: $45 \sim 55^{\circ} \mathrm{C}$ \\
\hline $\mathrm{NiCl}_{2} \times 6 \mathrm{H}_{2} \mathrm{O}: 40 \mathrm{~g} / \mathrm{l}$ & Current density: $0.6 \mathrm{~A} / \mathrm{dm}^{2}$ \\
\hline $\mathrm{H}_{3} \mathrm{BO}_{3}: 35 \mathrm{~g} / 1$ & Anode: $\mathrm{Ni}$ \\
\hline & $\begin{array}{c}\text { Cathode: martensitic } \\
\text { stainless steel sample } \\
\text { Thickness: } 20 \pm 0.2 \mu \mathrm{m}\end{array}$ \\
\hline $\mathrm{pH}: 3.8 \sim 4.5$ & \\
\hline
\end{tabular}

mass transport. Cui et al. ${ }^{32}$ developed multilayer $\mathrm{Cu}$ coatings using intermittent ultrasound during electrodeposition, and found corrosion and wear resistance as well as coating adhesion was enhanced, but hardness decreased.

In this work, an intermittent ultrasonic agitation is used in the Watt Ni electrodeposition course. This technique is promising because it is a simple and cost-effective method which is based on the simple combination of a conventional electrodeposition and a high-power ultrasonic irradiation. In this way, a novel kind of multilayered Ni coating, whose composition of each monolayer is the same, was successfully obtained by the ultrasound-assisted electrodeposition process. Its corrosion behavior and the microstructure were investigated systematically, compared with the ordinary Ni coatings.

\section{Experimental}

\subsection{Materials}

Martensitic stainless steel (1Cr11Ni2W2MoV) was used as the substrate and the cathode. Ni plates (purity: 99.97\%) were used as the anodes. Before electrodeposition, the substrates were grinded with $\mathrm{SiC}$ abrasive papers to 3000 grit under running water, and then cleaned in acetone solvent ultrasonically for $5 \mathrm{~min}$. The substrates were immersed in acid solution $(\mathrm{HCl}: 100 \mathrm{ml} / \mathrm{L}$ ) for about $3 \mathrm{~min}$, then washed by deionized water immediately before the electrodeposition. A nickel Watts' solution was used as the depositing solution. The compositions and electrodepositing parameters are listed in Table 1. The schematic diagram of the ultrasound-assisted electrodeposition device is shown in Figure 1. The electrodeposition cell was placed in the water

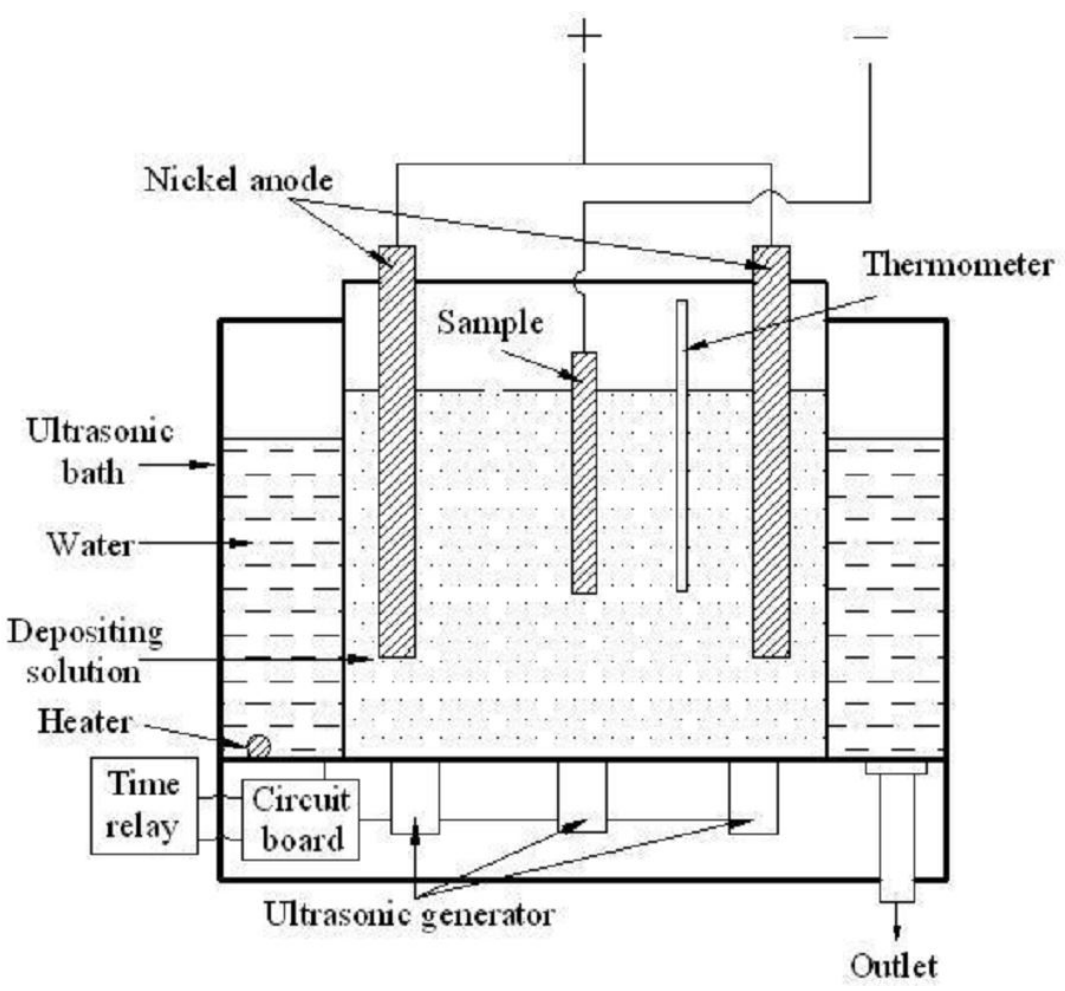

Figure 1. Schematic diagram of the ultrasound-assisted electrodeposition device. 
bath with the ultrasonic generators and heaters. The ultrasonic waves were introduced into the electrolyte by an ultrasound device (Model: CSF-1A, Shanghai, China). It should be pointed out that the ultrasonic mass-transfer distributions in the electrolyte ${ }^{33,34}$ are in the radial direction.

\subsection{Coating preparation}

The Ni coating was prepared without any ultrasonic agitation during the whole electrodepositing process, namely ordinary Ni coating. The process of multilayered Ni coatings is as follows:

1. During the deposition of multilayered Ni coatings, the mode of introducing ultrasound is that the ultrasonic wave was intermittently introduced at intervals with $60 \mathrm{~s}$. In this way, multilayered $\mathrm{Ni}$ coating is stacked by the ultrasonic Ni layers and the ordinary Ni layers alternately.

2. The power and frequency of ultrasound is $600 \mathrm{~W}$ and $25 \mathrm{kHz}$, respectively. The distance of the sample to the vessel bottom is about $1 \mathrm{~cm}$. The generator power is $600 \mathrm{~W}$ while the power intensity in the electrolyte is about $0.18 \mathrm{~W} / \mathrm{cm}^{3}$, measured by the calorimetric method ${ }^{35,36}$.

In order to compare the microstructure feature of the ordinary Ni layer with that of the ultrasonic Ni layer, a bilayered Ni coating was prepared as follows: an ultrasonic $\mathrm{Ni}$ layer was deposited with ultrasound for $30 \mathrm{~min}$ and then the ordinary Ni layer was deposited for $30 \mathrm{~min}$ without ultrasound.

\subsection{Characterization}

Surface and cross section morphologies of the Ni coatings were observed by scanning electron microscope (SEM) (XL-30FEG). An etchant solution $\left(10 \mathrm{~mL} \mathrm{HNO}_{3}, 10 \mathrm{~mL} \mathrm{CH}_{3} \mathrm{COOH}\right.$, $15 \mathrm{~mL} \mathrm{HCl}$ and 3 drops glycerol) was used in order to highlight the microstructure in the multilayered coatings. The porosity of the coatings was calculated using porosity analysis software on an optical microscope (MEF-4).

\subsection{Corrosion tests}

Electrochemical tests were carried out in $3.5 \% \mathrm{NaCl}$ aqueous solution at room temperature. Experiments were started after immersing the specimens into the solution for $10 \mathrm{~min}$. A platinum electrode, a saturated calomel electrode (SCE) and coated samples were used as counter electrode, reference electrode and working electrodes, respectively. All potentials are referred to SCE. Electrochemical impedance spectroscopy (EIS) spectra were acquired with $\mathrm{AC}$ frequencies ranging from $10^{5} \mathrm{~Hz}$ to $10^{-3} \mathrm{~Hz}$ using an EG\&G273 electrochemical system. The impedance spectra were acquired at a time interval of every 4 hours. Then, potentiodynamic polarization was performed in the applied potential range from $100 \mathrm{mV}$ below the corresponding $\mathrm{E}_{\mathrm{Corr}}$ to $+350 \mathrm{mV}$. ZSimpWin software was used for the data fitting. The static corrosion experiments were carried out in 7 vol. \% $\mathrm{HCl}$ solution at room temperature. Mass loss of the samples after immersion was measured with a FA1104N type single pan balance. After immersion for $10 \mathrm{~min}, \mathrm{X}$-ray photoelectron spectroscopy (XPS) analyses were carried out using ESCALAB 250. The XPS patterns were deconvoluted by the XPSPEAK software.

\section{Results}

\subsection{Microstructure of the coatings}

Cross sectional morphologies of the bilayered $\mathrm{Ni}$ coating and the multilayered Ni coating are shown in Figures $2 \mathrm{a}$ and $2 \mathrm{~b}$, respectively. From Figure $2 \mathrm{a}$, it can be observed that the microstructure feature of the top ordinary Ni layer is obviously different from that of the ultrasonic Ni sublayer. The grains of ordinary Ni layer are columnar, vertically to the substrate surface, but in contrast the grains of ultrasonic Ni layer grow parallel along the substrate surface. The main reason is that ultrasonic vibrator in the electrolyte emits strong wave signals with high frequency, high pressure and strong vibrations, which are converted to mechanical vibrations in the electrolyte bath. The ultrasonic power enhances the electrochemical process by increasing electron transfer, and the effective sonochemical process can cause more cavity/solvent interfaces and promote more violent bubble collapse $\mathrm{e}^{37}$. The ultrasonic waves spread in a mode of continuous, radial and straight line just along the grain arrangement of the ultrasonic Ni layer in Figure 2a. It resulted from the producing small negative pressure bubbles, which were broken out on the cathode surface intensively
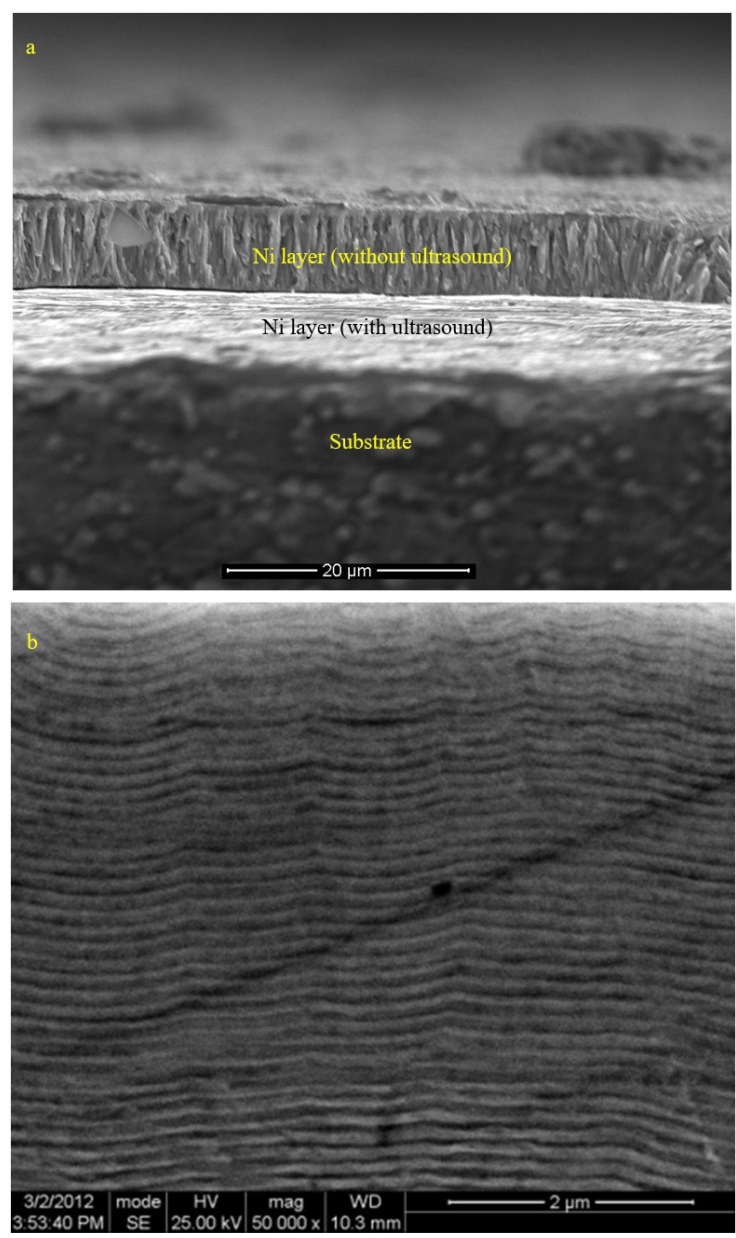

Figure 2. SEM images of the cross section of Ni coatings. (a) bilayered Ni coating (b) multilayered Ni coating. 
and continuously. This behavior enhances the instantaneous surface activity and increases the nucleation rate greatly ${ }^{38}$. As a result, the epitaxial growth of columnar Ni grains was markedly suppressed.

From Figure $2 b$, it can be observed that the microstructure of multilayered Ni coating is clearly a structure of stacked-up sandwiches. The white layers are the ultrasonic Ni layers and the dark ones are the ordinary Ni layers. From Figures $2 a$ and $2 b$, it can be considered as textured that the ordinary layers are vertically situated and the ultrasonic layers are horizontal. Therefore, the multilayered coating can entirely get rid of the straightforward pinhole formation ${ }^{39,40}$. In case of the traditional multilayered coatings, the compositions of any monolayer are different from those of its adjacent layers so that the crystallization kind, crystallographic lattice constant and grain size are different at the interface of two adjacent layers $^{41-45}$. However, in our multilayered Ni coating, the inherent pinholes are originally epitaxial, but are cut off by the ultrasonic Ni layers, due to the totally different growth mode for the ordinary and ultrasonic Ni layers. In other words, their growth directions change at the interfaces, so that the formation of pinholes can be effectively suppressed by the multilayered structure.

Figures $3 \mathrm{a}$ and $3 \mathrm{~b}$ show the micrographs of ordinary $\mathrm{Ni}$ coating and multilayered Ni coating, respectively. Some pinholes can be observed on the ordinary $\mathrm{Ni}$ coating in Figure $3 \mathrm{a}$, and these are also present in other researches ${ }^{46-48}$. In Figure 3b, no pinholes can be observed, even in a much higher resolution $(40000 \times)$ than that of ordinary Ni coating $(10000 \times)$. The porosity test results show that the ordinary Ni coating contains about 34 pinholes per square centimeter, but no pinholes can be observed in the multilayered Ni coating.

\subsection{Corrosion tests}

EIS is an excellent method to identify the corrosion mechanism and kinetics. The Nyquist plot is a semicircular plot between the electrochemical real and imaginary impedance in Figure 4 and the EIS data can be explained by means of simple electrical circuits as shown in Figure 5.
Corrosion resistance of a coating can be explained by two different circuits: i. one-time constant circuit as shown in Figure 5a where the solution resistance $\left(R_{S}\right)$ is in series with the double layer capacitance $\left(\mathrm{Q}_{\mathrm{dl}}\right)$, which is in turn parallel to a charge transfer resistance or polarization resistance $\left(\mathrm{R}_{\mathrm{p}}\right)$; ii. two-time constant circuit in Figure $5 \mathrm{~b}$ is utilized. Here, an embedded parallel resistance $\left(R_{2}\right)$ and a capacitance $\left(Q_{2}\right)$ are in series with the main Randles circuit ${ }^{49}$. The two resistances $\mathrm{R}_{1}$ and $\mathrm{R}_{2}$ in the two $\mathrm{Ni}$ coatings can be characterized as the polarization resistance of the corrosion product and the coating, respectively. The impedance is given by the Equation 1

$Z_{Q}=\left(Y_{0} J \omega^{n}\right)^{-1}$

where $\mathrm{Z}$ is the impedance $(\Omega), Y_{0}$ is the capacitance factor $\left(\Omega^{-1} \cdot \mathrm{s}^{\mathrm{n}}\right), \omega$ is the angular frequency $\left(\mathrm{rad} \cdot \mathrm{S}^{-1}\right)$, and $n$ is the empirical exponent of $Q$. When $Q$ is close to 1 , the behavior can be equalized to a double layer capacitance. In a Nyquist plot, the polarization resistance approximately corresponds to the size of the semicircle ${ }^{50}$. EIS spectra of ordinary Ni coating and multilayered Ni coating are shown in Figure 4. EIS parameters determined from the equivalent circuit models are shown in Table 2 for the two Ni coatings. The Nyquist plots of ordinary Ni coating exhibit two-time constants, which is characterized by the appearance of two semi-circles. The quick response for the two-time constants implies the existence of the pinholes. The presence of fine pinholes in ordinary $\mathrm{Ni}$ coating shows an inferior degree of coating protection against $\mathrm{NaCl}$ corrosion. This behavior eliminated until $8 \mathrm{~h}$ and then the character changed into one-time constant. With the increasing exposure time, the pinholes were filled with adhesive corrosion products, which could protect the following corrosion attack. Then, corrosion resistance of the coating increased progressively due to $\mathrm{Ni}$ enrichment on the surface. Unlike ordinary $\mathrm{Ni}$ coating, multilayered $\mathrm{Ni}$ coating shows one-time constant during the whole $24 \mathrm{~h}$ exposure cycle, indicating that the $\mathrm{NaCl}$ solution did not penetrate the coating to the substrate after the 24-hour immersion time due to the multilayered structure. Since it was too difficult for the $\mathrm{NaCl}$ solution
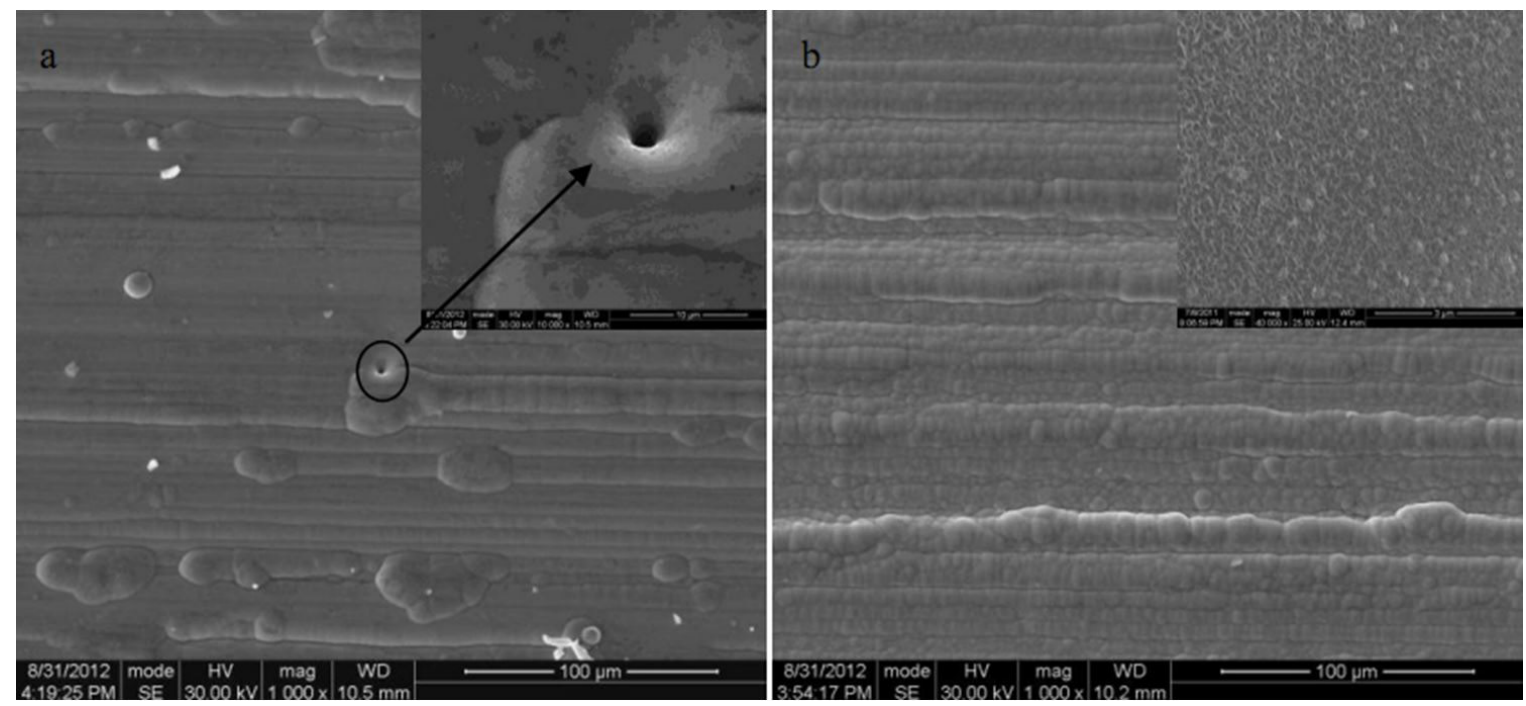

Figure 3. Surface SEM images of Ni coatings. (a) ordinary Ni coating. (b) multilayered Ni coating. 

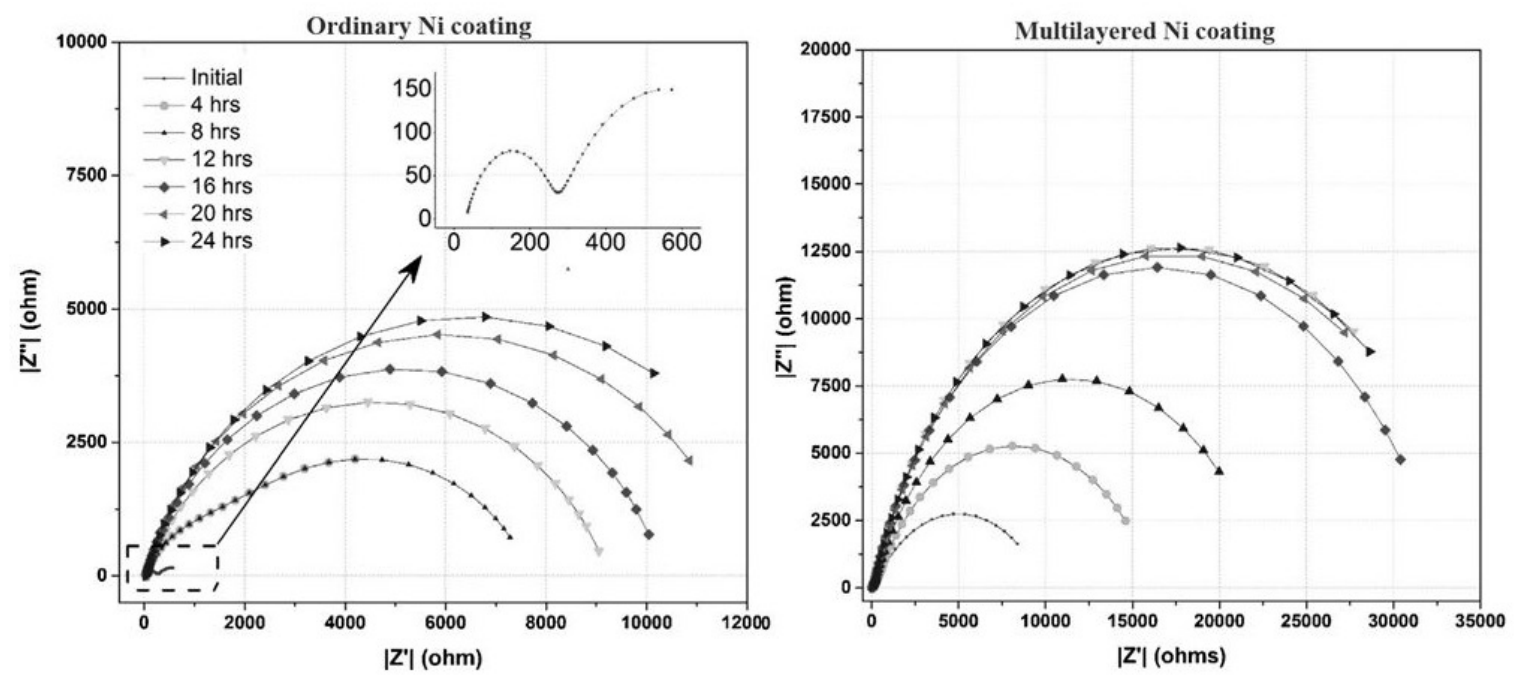

Figure 4. Nyquist plots of ordinary Ni coating and multilayered Ni coating in 3.5\% $\mathrm{NaCl}$ solution for immersion time more than $24 \mathrm{~h}$ at $298 \mathrm{~K}$.

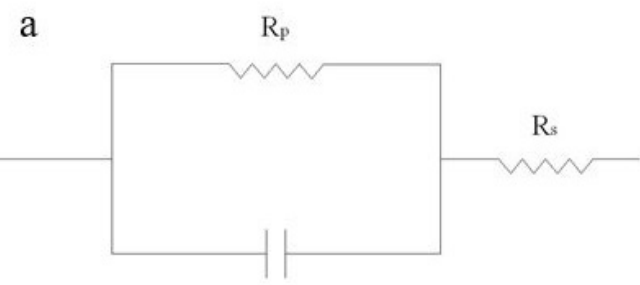

Qdl

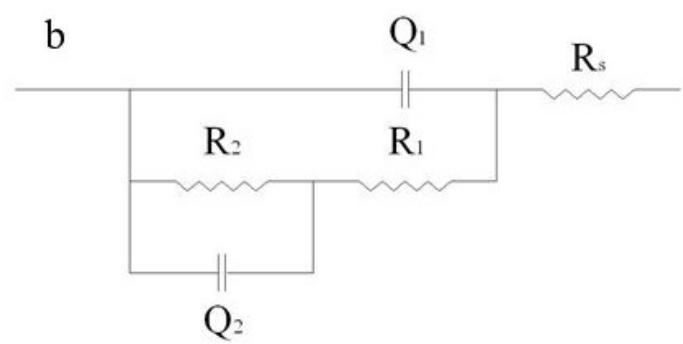

Figure 5. Equivalent circuit models used for fitting the Nyquist data. (a) one-time constant. (b) two-time constants.

Table 2. Equivalent circuit parameters of the Ni coatings from the Nyquist plots.

\begin{tabular}{|c|c|c|c|c|c|c|c|}
\hline \multirow{2}{*}{ Elapsed time (h) } & \multirow{2}{*}{$\mathrm{R}_{\mathrm{S}}(\mathrm{K} \Omega)$} & \multirow{2}{*}{$\mathrm{R}_{1}(\mathrm{~K} \Omega)$} & \multicolumn{2}{|c|}{$\mathrm{Q}_{1}$} & \multirow{2}{*}{$\mathrm{R}_{2}(\mathrm{~K} \Omega)$} & \multicolumn{2}{|c|}{$\mathrm{Q}_{2}$} \\
\hline & & & $Y_{0}$ & $\mathrm{n}$ & & $\mathrm{Y}_{0}$ & $\mathrm{n}$ \\
\hline \multicolumn{8}{|l|}{ Ordinary Ni coating } \\
\hline 0 & 0.033 & 0.2487 & $5.76 \mathrm{E}-06$ & 0.73 & 0.603 & $1.92 \mathrm{E}-03$ & 0.57 \\
\hline 4 & 0.035 & 2.737 & $6.08 \mathrm{E}-05$ & 0.80 & 5.24 & $2.61 \mathrm{E}-04$ & 0.76 \\
\hline 8 & 0.035 & 9.46 & $1.22 \mathrm{E}-04$ & 0.79 & 6.79 & $1.64 \mathrm{E}-04$ & 0.79 \\
\hline 12 & 0.0348 & 10.91 & $1.59 \mathrm{E}-04$ & 0.80 & & & \\
\hline 16 & 0.0343 & 10.19 & $1.87 \mathrm{E}-04$ & 0.81 & & & \\
\hline 20 & 0.0344 & 11.84 & $2.04 \mathrm{E}-04$ & 0.82 & & & \\
\hline 24 & 0.0344 & 12.73 & $2.22 \mathrm{E}-04$ & 0.81 & & & \\
\hline \multicolumn{8}{|c|}{ Multilayered Ni coating } \\
\hline 0 & 0.0282 & 0.384 & $9.47 \mathrm{E}-07$ & 0.83 & & & \\
\hline 4 & 0.0286 & 0.621 & $1.59 \mathrm{E}-06$ & 0.72 & & & \\
\hline 8 & 0.0293 & 0.520 & $1.25 \mathrm{E}-06$ & 0.87 & & & \\
\hline 12 & 0.0303 & 0.249 & $1.04 \mathrm{E}-06$ & 0.77 & & & \\
\hline 16 & 0.0305 & 0.218 & $1.59 \mathrm{E}-06$ & 0.78 & & & \\
\hline 20 & 0.0304 & 0.305 & $1.61 \mathrm{E}-06$ & 0.77 & & & \\
\hline 24 & 0.0303 & 0.310 & $1.64 \mathrm{E}-06$ & 0.76 & & & \\
\hline
\end{tabular}

to penetrate through the very long pinholes, which were extended by the multilayered structure, the shape of the Nyquist plot depends on the penetration depth ( $r$ ) of the solution and pinhole length $(1)^{51}$. The shape of Nyquist plots obtained from multilayered $\mathrm{Ni}$ coating is a semi-circle, which is similar to the limiting case when $1 \gg r$ and the AC signal manages to reach not the substrate but the bottom of the pinhole. In such cases, the entire electrode behaves as a flat surface, which is independent of the substrate.

Figure 6 shows the potentiodynamic polarization curves in $3.5 \% \mathrm{NaCl}$ solution for the multilayered $\mathrm{Ni}$ coating and the ordinary Ni coating at room temperature. The corrosion 
potential $\left(\mathrm{E}_{\text {corr }}\right)$ and corrosion current density $\left(\mathrm{I}_{\text {corr }}\right)$ were obtained from the potentiodynamic polarization curves are listed in Table 3. I corr $_{\text {was }}$ wetermined by extrapolating the straight-line section of the anodic and cathodic Tafel lines ${ }^{52}$. In Figure 6 , the cathode behavior in the polarization curves corresponded to the hydrogen evolution, and the anodic behavior was the most important features, i.e. the corrosion resistance. It is noted that corrosion resistance of materials or coatings has a close relationship to their passivity-maintaining current densities in the polarization curves. Passivity-maintaining current density can remain stable as the potential increases within a certain potential zone. From E-I plots, it is evident that the multilayered $\mathrm{Ni}$ coating exhibits a much lower passivity current density (about $10 \mu \mathrm{A} / \mathrm{cm}^{2}$ ), over a wide potential range $(-0.26$ to $+0.03 \mathrm{~V})$. Moreover, $\mathrm{E}_{\text {corr }}$ of the multilayered Ni coating shifted positively about $180 \mathrm{mV}$, and $\mathrm{I}_{\text {corr }}$ decreased from $3.98 \mu \mathrm{A} / \mathrm{cm}^{2}$ (ordinary Ni coating) to $1.12 \mu \mathrm{A} / \mathrm{cm}^{2}$ (multilayered $\mathrm{Ni}$ coating) approximately.

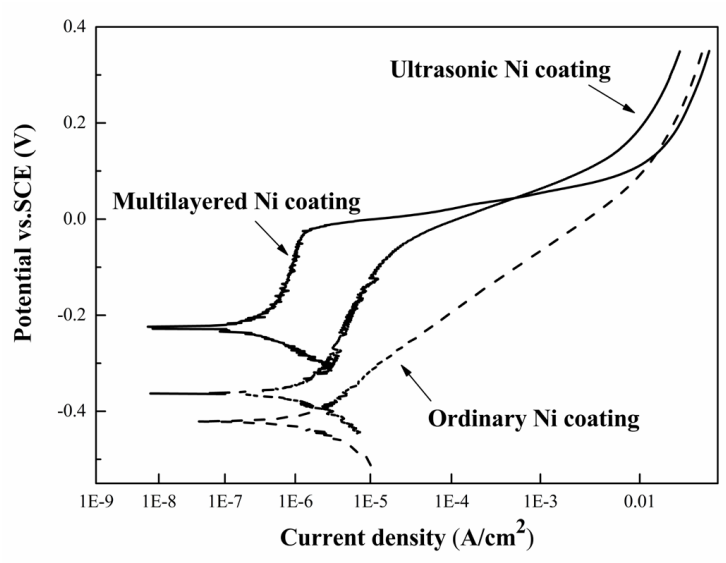

Figure 6. Potentiodynamic polarization curves for the Ni coatings in $3.5 \% \mathrm{NaCl}$ solution at $298 \mathrm{~K}$.

Table 3. Corrosion parameters of the investigated coatings in 3.5\% $\mathrm{NaCl}$ solution derived from potentiodynamic polarization curves.

\begin{tabular}{ccc}
\hline Type of coating & $\mathrm{E}_{\text {corr }}[\mathrm{mV}]$ & $\mathrm{I}_{\text {corr }}\left[\mu \mathrm{A} / \mathrm{cm}^{2}\right]$ \\
\hline Ordinary Ni coating & -0.42 & 3.98 \\
\hline Multilayered Ni coating & -0.24 & 0.49 \\
\hline
\end{tabular}

The polarization response of the ordinary Ni coating shows two sequential processes, including a cathode evolution of $\mathrm{H}_{2}$ and an anodic dissolution. No passive region can be identified, implying the poor corrosion resistance of ordinary $\mathrm{Ni}$ coating. Concerning the distinct passivity regime for the multilayered Ni coating, it is evident that the multilayered structure significantly promotes corrosion resistance.

Figure 7 shows the mass loss exposed to 7 vol.\% $\mathrm{HCl}$ solution. From Figure 7, mass loss of multilayered Ni coating is only $0.093 \mathrm{mg} / \mathrm{cm}^{2}$ after immersion for $48 \mathrm{~h}$, but mass loss of ordinary Ni coating seriously reached $1.066 \mathrm{mg} / \mathrm{cm}^{2}$ for only $2 \mathrm{~h}$. It is expectable, based on the polarization data. It can be concluded that corrosion rate of the ordinary $\mathrm{Ni}$ coating is much faster than that of the multilayered Ni coating.

\section{Discussions}

The effect of corrosion protection of the martensite steel substrate by multilayer coatings in contrast to single coatings is ascribed to the selective dissolution of several layers with alternatively varying composition ${ }^{23,53,54}$. A similar preferential dissolution of less noble element from the alloy is a well-known demetallization can occur as confirmed by the literatures ${ }^{55,56}$. However, in our study, no element difference between the layers can be detected, i.e. no preferential dissolution of element or layers can occur during the corrosion. Thus, the corrosion mechanism can vary from those studies.

Primarily, the compositions of the passive film of both Ni coatings should be investigated by XPS profiles after immersion in 7 vol. $\% \mathrm{HCl}$ solution for $10 \mathrm{~min}$, shown in Figure 8 . The XPS analysis suggests that the surface of the ordinary Ni coating contains mostly $\mathrm{Ni}(852.7 \mathrm{eV})$ with hydrated nickel oxide $-\mathrm{Ni}(\mathrm{OH})_{2}(856.4 \mathrm{eV})$ as a secondary component. The $\mathrm{NiO}$ curve cannot be deconvoluted by the XPSPEAK software for the ordinary Ni coating, since the $\mathrm{NiO}$ curve is almost in coincidence with the base line. On the other hand, the surface film of the multilayered Ni coating is comprised of $\mathrm{NiO}(853.5 \mathrm{eV})$ and $\mathrm{Ni}(\mathrm{OH})_{2}(856.4 \mathrm{eV})$, with $\mathrm{Ni} 2 \mathrm{p}$ peak at $852.5 \mathrm{eV}$ as a major component. It was reported that the passive film with bilayered structure contained an inner barrier layer of protective $\mathrm{NiO}$ and an outer layer of anhydrous $\mathrm{Ni}(\mathrm{OH})_{2}$, and this integrated bilayered structure greatly inhibited the corrosion of $\mathrm{Ni}^{57}$. Nickel(II) oxide (NiO) is confirmed as the main component, which is responsible

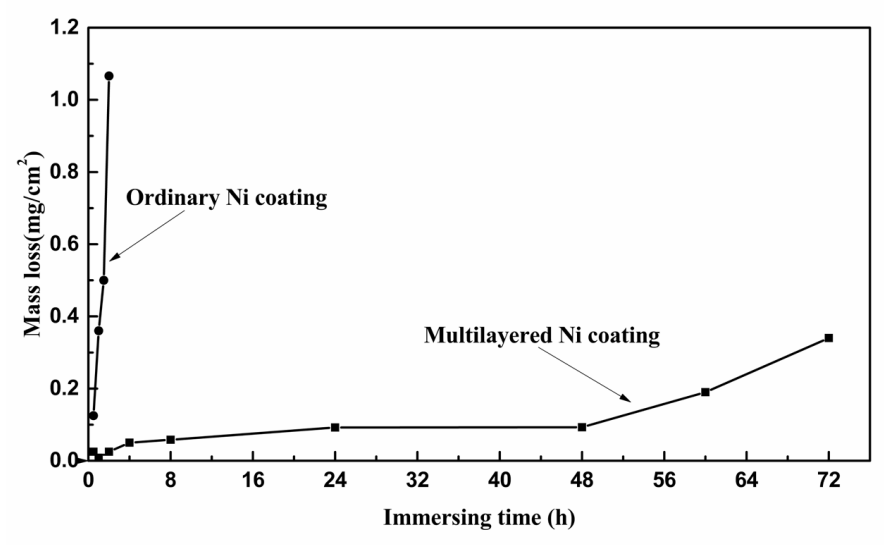

Figure 7. Immersing experiment results of the Ni coating samples in $7 \mathrm{vol} . \% \mathrm{HCl}$ solution. 

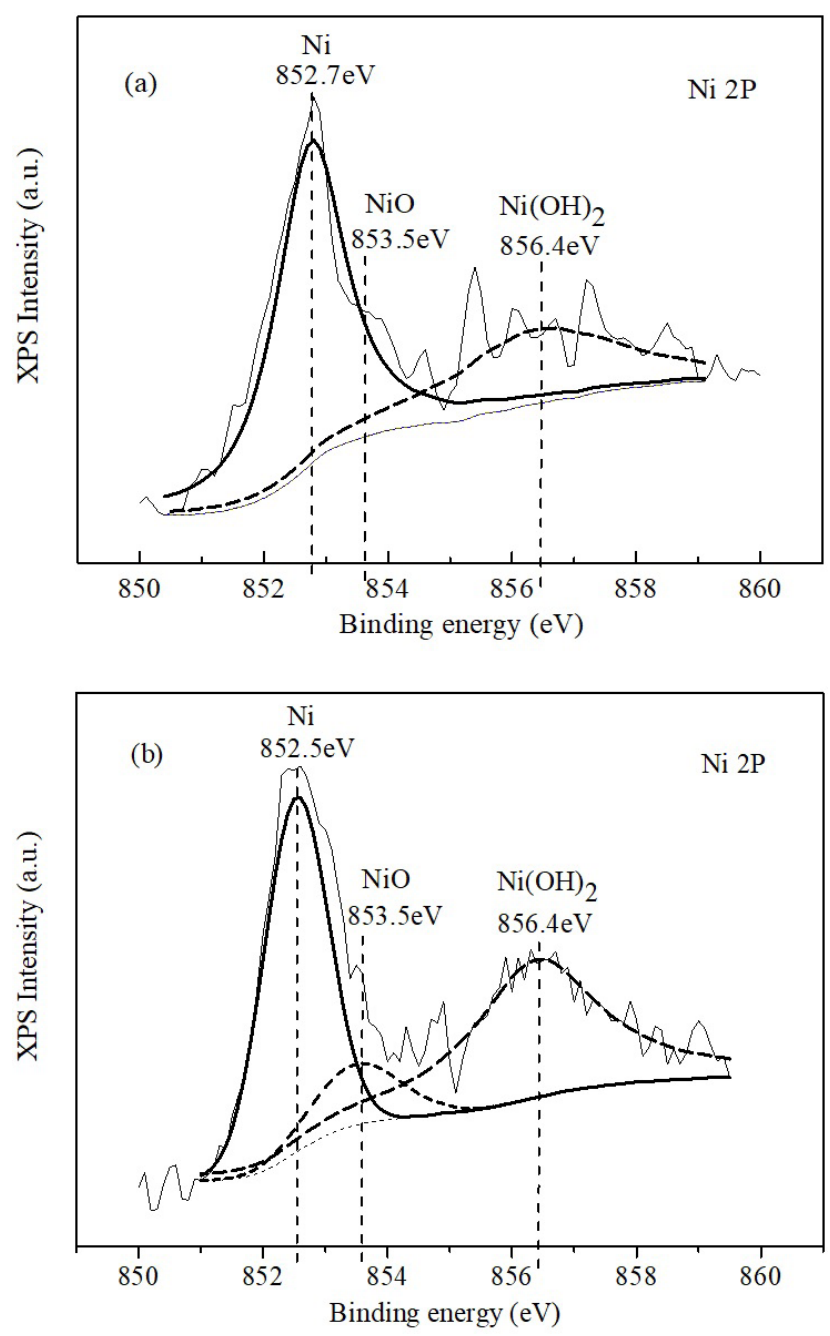

Figure 8. Ni 2p XPS peaks for the passive film after immersing in 7 vol. $\% \mathrm{HCl}$ solution. (a) ordinary Ni coating. (b) multilayered Ni coating.

for passivity on nickel in acidic environments ${ }^{58}$. Thereby, $\mathrm{NiO}$ layer is a significant component in the passive film. Once the integrated passive oxide film on the multilayered $\mathrm{Ni}$ coating is formed, it cannot be easily removed by either cathodic treatment or chemical dissolution.

In order to interpret the absence of the $\mathrm{NiO}$ layer in the passive film of ordinary $\mathrm{Ni}$ coating, the representative schematic kinetic behavior of $\mathrm{H}_{2} \mathrm{O}$ diffusion at the defect of pinholes in the coatings is shown in Figure 9, which is also reported in the literatures ${ }^{59,60}$. The directions and sizes of the arrows mean the transferring direction and the speed of $\mathrm{H}_{2} \mathrm{O}$ diffusion, respectively. The isoconcentration curves of $\mathrm{H}_{2} \mathrm{O}$ are formed by the arrow tips when the coating sample was immersed in the $\mathrm{HCl}$ aqueous solution for some time. Commonly, the $\mathrm{H}_{2} \mathrm{O}$ transferring is preferably diffused through the coating defect, i.e. pinholes. In the perfect state, the passive film is continuous and complete. In fact, the condensed pinholes break the integrity of the passive film, which is only several nanometers in thickness, so that the $\mathrm{NiO}$ layer is diffused and hydrated by the water for the ordinary $\mathrm{Ni}$ coating, turning into $\mathrm{Ni}(\mathrm{OH})_{2}$. This is one proof.
In addition, after the static corrosion experiment, the surface morphologies of the Ni coatings were observed in Figures 10 and 11 . The results show that not only did a few pits occur on the sample surface for the ordinary Ni coating, but also the representative open corrosion pits (Figure 10b) were generated. Many active corrosion sites, i.e. pinholes, can accelerate partial corrosion. They are distributed throughout the whole coating surface and thus decrease the overall anodic overpotential. The substrate was partially exposed (Figure 12a) due to the pinholes even if the adjacent surface of the pinholes did not corrode at all. As we all know, the pinholes are direct passages which can corrode the substrate immediately, in order that the hydrogen can be released via the passages. Moreover, Figure 10c reveals that the ordinary Ni deposit shows big cracks all over the coating surface as the immersing time was increased. In most studies, a net of microcracks was observed during dissolution ${ }^{11,62}$. The formation of microcracks or pores were contributed to secondary reaction of hydrogen evolution. The production of cracks in chloride media could deteriorate the properties of the electrodeposited Ni coatings, specially the stability. It was reported that $\mathrm{Ni}-\mathrm{W}$ films with cracks showed lower 
corrosion resistance ${ }^{63}$. Additionally, in the rings of Figure 12a, another corrosion mechanism of the ordinary Ni coating is the formation of $\mathrm{Fe} / \mathrm{Ni}$ galvanic couples ${ }^{64,65}$ - corrosion microbattery is generated - via the connective corrosive media by pinholes. Oxygen and halide ions intrude into the substrate directly, and then corrosion microbattery and even oxide of Fe can be formed at the $\mathrm{Fe} / \mathrm{Ni}$ interface. It is found by SEM inspection in Figures $3 \mathrm{a}$ and $10 \mathrm{~b}$ that the initial

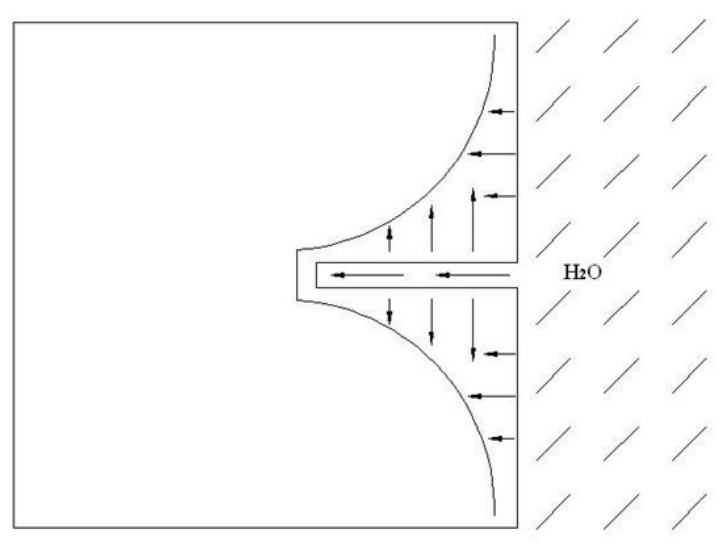

Figure 9. Schematic kinetic behavior of $\mathrm{H}_{2} \mathrm{O}$ diffusion at the defect of pinholes in the coating.
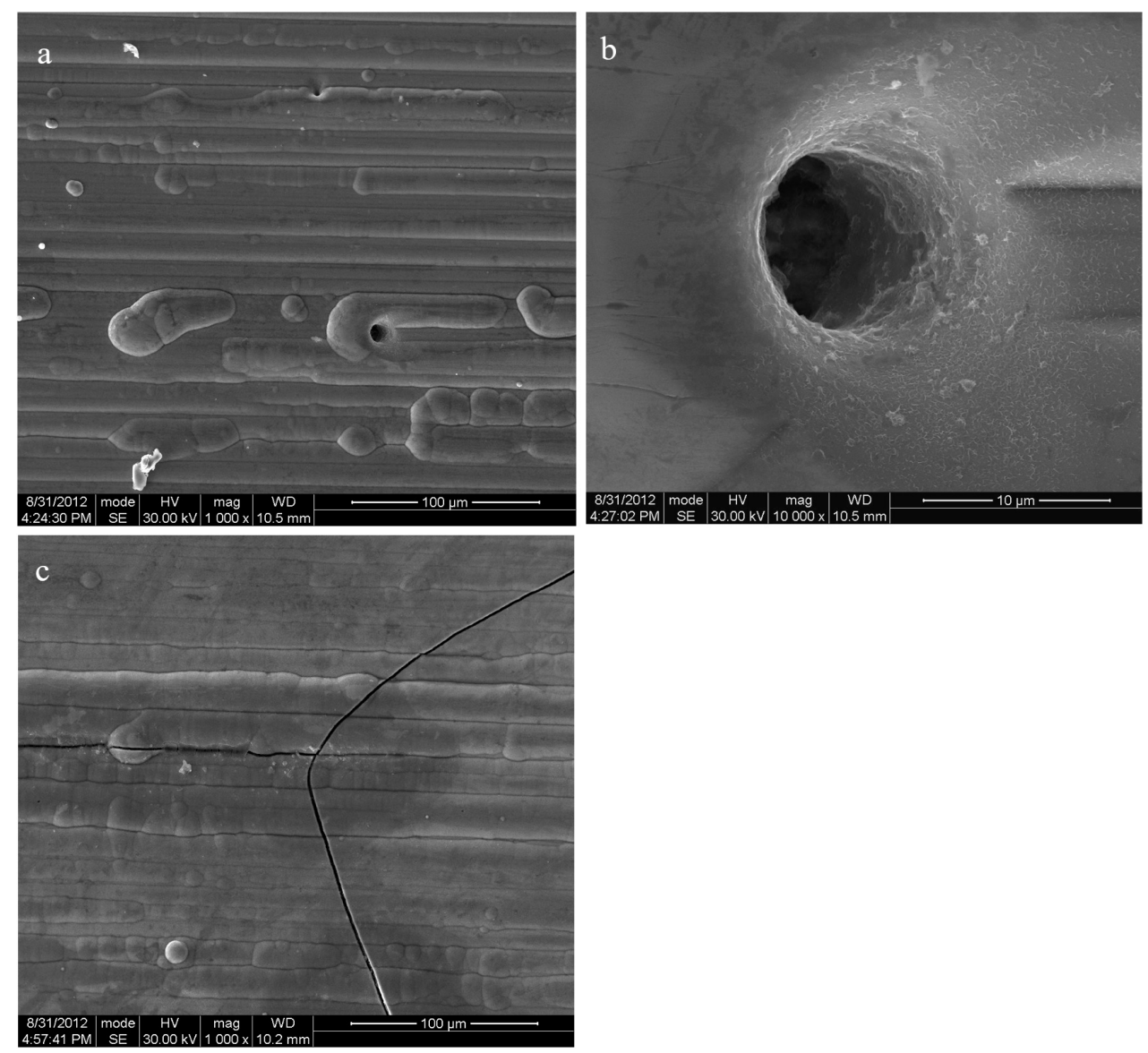

Figure 10. SEM micrographs of ordinary Ni coatings at various exposed time in 7 vol.\% $\mathrm{HCl}$ solution. (a) 10 min, (b) higher resolution in Figure 10a, c 20 min. corrosive solution could penetrate the coating easily, i.e. corrosion pits, and the drastic action of corrosion behavior on the substrate could arise. The corrosion micro-battery and even oxide of $\mathrm{Fe}$ at the coating/substrate interface can greatly lower the adhesion of the coating and the substrate, and then the breakdown of the protective Ni coating would occur when pits covered the whole coating surface. Eventually, the coating system will disaggregate. This behavior can be coincident with the EIS spectrum of the ordinary Ni coating, the quick response of two-time constants from the initial stage to $8 \mathrm{~h}$ immersion. As the samples were immersed in neutral solution containing $\mathrm{Cl}^{-}$ions in the electrochemical test, the corrosion attack is much slower than that of the samples immersed in $\mathrm{HCl}$ solution. Both immersions can prove the pinhole existence for the ordinary $\mathrm{Ni}$ coating.

On the contrary, it can be observed in Figure 11a and 11b that the continuous and compact grains were distributed homogeneously without any pinholes. Just as Figure 11b, the multilayered structure can extend a long distance tremendously when the corrosive solution could reach the substrate through the multilayered Ni coating, because the parallel ultrasonic Ni layers inhibit the pinholes of the columnar ordinary Ni layers. Therefore, corrosion of the multilayered Ni coating occurred at the localized corrosion of the coating surface, which is irrespective of the substrate corrosion. Hence, samples with multilayered Ni coating can avoid the dissolution behavior of 

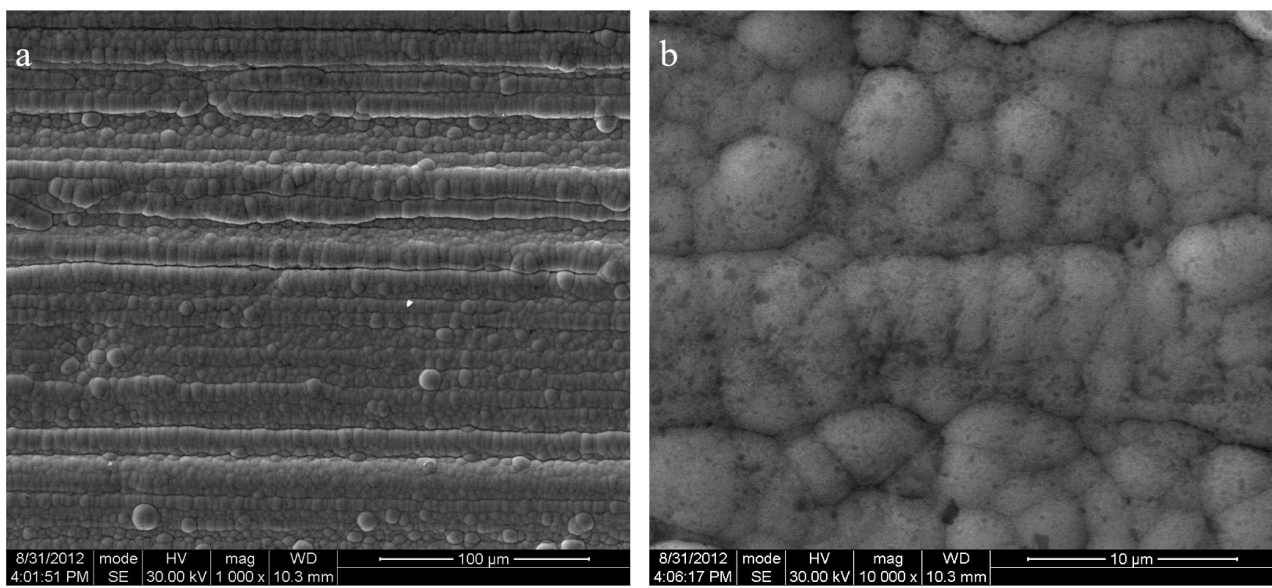

Figure 11. SEM micrographs of multilayered Ni coatings at various exposed time in 7 vol. $\% \mathrm{HCl}$ solution. (a) 30 min (b) higher resolution in Figure 11a.
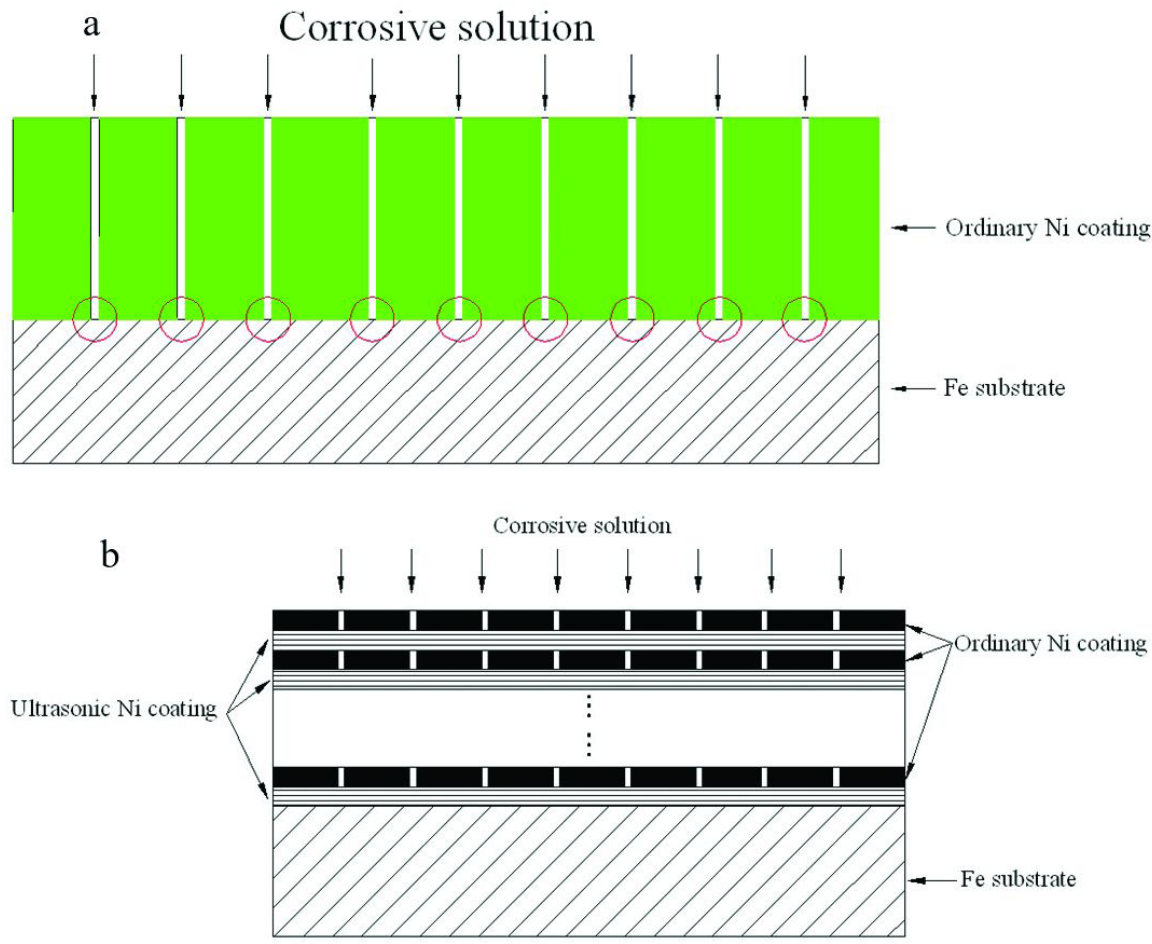

Figure 12. Schematic diagrams of corrosion mechanism of Ni coatings. (a) ordinary Ni coating (b) multilayered Ni coating.

the substrate and thus increase the overall anodic overpotential. The hydrogen cavities as discussed in the ordinary Ni coating cannot occur on the multilayered $\mathrm{Ni}$ coating, in respect that there are no pinholes at all. Therefore, the corrosive solution cannot reach the substrate, in order that hydrogen evolution can be reduced seriously. Moreover, the passive film formed on the sample surface was integrated for the multilayered $\mathrm{Ni}$ coating according to Figure $12 \mathrm{~b}$, which was also validated by XPS measurement. The inner protective barrier layer of $\mathrm{NiO}$ was easily formed beneath the $\mathrm{Ni}(\mathrm{OH})_{2}$ layer. In this case, the passive film plays a vital role in anti-corrosion behavior for the multilayered $\mathrm{Ni}$ coating. The analysis of the multilayered Ni coating presents a uniform corrosion.
Therefore, better corrosion resistance of the multilayered Ni coating is attributed to the absence of the pinholes and its integrated passive film.

\section{Conclusions}

Multilayered Ni coating is successfully obtained by electrodeposition method with intermittent ultrasound. It is the multilayered microstructure of stacked-up sandwiches, in which the compositions of any monolayer are almost the same to those of its adjacent layers.

Corrosion resistance of the multilayered Ni coating is much better than that of the ordinary Ni coating. The multilayered 
structure can eliminate the formation of pinholes running through the coating. The multilayered structure extends the corrosive passages tremendously, so that it can remarkably impede the straight invasion of the corrosion media to the substrate. Therefore, corrosion mechanism of the ordinary Ni coating is corroded through a large number of pinholes, while that of the multilayered $\mathrm{Ni}$ coating is converted into the uniform corrosion.

\section{Acknowledgements}

The authors gratefully acknowledge the financial support of the project from the National Natural Science Foundation of China (No. 51701223).

\section{References}

1. Pourbaix M. Applications of electrochemistry in corrosion science and in practice. Corros Sci. 1974;14(1):25-82. http:// dx.doi.org/10.1016/S0010-938X(74)80006-5.

2. Miranda FJF, Barcia OE, Mattos OR, Wiart R. Electrodeposition of Zn-Ni alloys in sulfate electrolytes: I. experimental approach. J Electrochem Soc. 1997;144(10):3441-9. http://dx.doi. org/10.1149/1.1838030.

3. Chen Y. Practical electrodeposition technology. Beijing: National Defence Industrial Press; 2003.

4. García-Lecina E, García-Urrutia I, Díez JA, Morgiel J, Indyka P. A comparative study of the effect of mechanical and ultrasound agitation on the properties of electrodeposited Ni/A12O3 nanocomposite coatings. Surf Coat Tech. 2012;206(11-12):29983005. http://dx.doi.org/10.1016/j.surfcoat.2011.12.037.

5. Ma CB, Cao FH, Zhang Z, Zhang JQ. Electrodeposition of amorphous Ni-P coatings onto Nd-Fe-B permanent magnet substrates. Appl Surf Sci. 2006;253(4):2251-6. http://dx.doi. org/10.1016/j.apsusc.2006.04.037.

6. Arunsunai Kumar K, Paruthimal Kalaignan G, Muralidharan VS. Pulse electrodeposition and characterization of nano $\mathrm{Ni}-\mathrm{W}$ alloy deposits. Appl Surf Sci. 2012;259:231-7. http://dx.doi. org/10.1016/j.apsusc.2012.07.024.

7. Hari SN. Nanostructure materials and nanotechnology. San Diego: Academic Press; 2002.

8. Narasimman P, Pushpavanam M, Periasamy VM. Wear and scratch resistance characteristics of electrodeposited nickelnano and micro SiC composites. Wear. 2012;292-293:197-206. http://dx.doi.org/10.1016/j.wear.2012.05.009.

9. Lajevardi SA, Shahrabi T, Szpunar JA. Synthesis of functionally graded nano Al2O3-Ni composite coating by pulse electrodeposition. Appl Surf Sci. 2013;279:180-8. http://dx.doi.org/10.1016/j. apsusc.2013.04.067.

10. Gyftou P, Pavlatou EA, Spyrellis N. Effect of pulse electrodeposition parameters on the properties of Ni/nano-SiC composites. Appl Surf Sci. 2008;254(18):5910-6. http://dx.doi.org/10.1016/j. apsusc.2008.03.151.

11. Wang L, Gao Y, Xu T, Xue Q. Corrosion resistance and lubricated sliding wear behaviour of novel Ni-P graded alloys as an alternative to hard Cr deposits. Appl Surf Sci. 2006;252:7361-72.

12. Bakhit B, Akbari A. Effect of particle size and co-deposition technique on hardness and corrosion properties of $\mathrm{Ni}-\mathrm{Co} / \mathrm{SiC}$ composite coatings. Surf Coat Tech. 2012;206(23):4964-75. http://dx.doi.org/10.1016/j.surfcoat.2012.05.122.

13. Fenker M, Balzer M, Kappl H. Corrosion protection with hard coatings on steel: past approaches and current research efforts. Surf Coat Tech. 2014;257:182-205. http://dx.doi.org/10.1016/j. surfcoat.2014.08.069.

14. Dennis JK, Such TE. Nickel and chromium plating. USA: Elsevier; 1993. http://dx.doi.org/10.1533/9781845698638.
15. Ghosh SK, Singh S, Basu S. Structural and magnetic characterization of electrodeposited $\mathrm{Ni} / \mathrm{Cu}$ multilayers. Mater Chem Phys. 2010;120(1):199-205. http://dx.doi.org/10.1016/j. matchemphys.2009.10.046.

16. Etminanfar MR, Heydarzadeh Sohi M. Corrosion resistance of multilayer coatings of nanolayered $\mathrm{Cr} / \mathrm{Ni}$ electrodeposited from Cr(III)-Ni(II) bath. Thin Solid Films. 2012;520(16):5322-7. http://dx.doi.org/10.1016/j.tsf.2012.03.127.

17. Fei JY, Wilcox GD. Electrodeposition of zinc-nickel compositionally modulated multilayer coatings and their corrosion behaviours. Surf Coat Tech. 2006;200(11):3533-9. http://dx.doi.org/10.1016/j.surfcoat.2004.08.183.

18. Wasekar NP, Gowthami S, Jyothirmayi A, Joardar J, Sundararajan G. Corrosion behaviour of compositionally modulated nanocrystalline Ni-W coatings. Surf Eng. 2019;36(9):952-9. http://dx.doi.org/10.1080/02670844.2019.1660035.

19. Kirilova I, Ivanov I. Corrosion behaviour of Zn-Co compositionally modulated multilayers electrodeposited from single and dual baths. J Appl Electrochem. 1999;29(9):1133-7. http://dx.doi. org/10.1023/A:1003675216529.

20. Hovsepian PE, Lewis DB, Münz W-D. Recent progress in large scale manufacturing of multilayer/superlattice hard coatings. SurfCoat Tech. 2000;133-134:166-75. http://dx.doi.org/10.1016/ S0257-8972(00)00959-2.

21. Flores M, Muhl S, Andrade E. The relation between the plasma characteristic and the corrosion properties of TiN/Ti multilayers deposited by unbalanced magnetron sputtering. Thin Solid Films. 2003;433(1-2):217-23. http://dx.doi.org/10.1016/S00406090(03)00340-7.

22. Bahadormanesh B, Ghorbani M. Ni-P/Zn-Ni compositionally modulated multilayer coatings - Part 2: corrosion and protection mechanisms. Appl Surf Sci. 2018;442:313-21. http://dx.doi. org/10.1016/j.apsusc.2018.02.130.

23. Shetty AR, Chitharanjan Hegde A. Ultrasound induced multilayer Ni-Co alloy coatings for better corrosion protection. Surf Coat Tech. 2017;322:99-107. http://dx.doi.org/10.1016/j. surfcoat.2017.05.043.

24. Coleman S, Roy S. Effect of ultrasound on mass transfer during electrodeposition for electrodes separated by a narrow gap. Chem Eng Sci. 2014;113:35-44. http://dx.doi.org/10.1016/j. ces.2014.03.026.

25. Floate S, Hyde M, Compton RG. Electrochemical and AFM studies of the electrodeposition of cobalt on glassy carbon: an analysis of the effect of ultrasound. J Electroanal Chem (Lausanne Switz). 2002;523(1-2):49-63. http://dx.doi.org/10.1016/S00220728(02)00709-X.

26. Hyde ME, Compton RG. How ultrasound influences the electrodeposition of metals. J Electroanal Chem (Lausanne Switz). 2002;531(1):19-24. http://dx.doi.org/10.1016/S00220728(02)01016-1.

27. Touyeras F, Hihn JY, Bourgoin X, Jacques B, Hallez L, Branger V. Effects of ultrasonic irradiation on the properties of coatings obtained by electroless plating and electro plating. Ultrason Sonochem. 2005;12(1-2):13-9. http://dx.doi.org/10.1016/j. ultsonch.2004.06.002.

28. Xia FF, Wu MH, Wang F, Jia ZY, Wang AL. Nanocomposite $\mathrm{Ni}-\mathrm{TiN}$ coatings prepared by ultrasonic electrodeposition. Curr Appl Phys. 2009;9(1):44-7. http://dx.doi.org/10.1016/j. cap.2007.11.014.

29. Prasad PBSNV, Vasudevan R, Seshadri SK, Ahila S. The effect of ultrasonic vibration on nickel electrodeposition. Mater Lett. 1993;17(6):357-9. http://dx.doi.org/10.1016/0167577X(93)90125-H.

30. Zin V, Brunelli K, Dabalà M. Characterization of $\mathrm{Cu}-\mathrm{Ni}$ alloy electrodeposition and synthesis of nanoparticles by pulsed sonoelectrochemistry. Mater Chem Phys. 2014;144(3):272-9. http://dx.doi.org/10.1016/j.matchemphys.2013.12.028. 
31. Gyawali G, Cho SH, Woo DJ, Lee SW. Pulse electrodeposition and characterisation of $\mathrm{Ni}-\mathrm{SiC}$ composite coatings in presence of ultrasound. Transact. IMF. 2012;90(5):274-81. http://dx.doi. org/10.1179/0020296712Z.00000000043.

32. Cui RH, Yu ZM, He YT, Shu WJ. Copper Multilayer Coating Prepared by Ultrasonic-Electrodeposition. Adv Mat Res. 2010;97-101(v):1348-1351.

33. Trabelsi F, Ait-lyazidi H, Berlan J, Fabre P-L, Delmas H, Wilhelm AM. Electrochemical determination of the active zones in a high-frequency ultrasonic reactor. Ultrason Sonochem. 1996;3(2):S125-30. http://dx.doi.org/10.1016/13501477(96)00006-Y.

34. Pollet BG, Hihn J-Y, Mason TJ. Sono-electrodeposition (20 and $850 \mathrm{kHz}$ ) of copper in aqueous and deep eutectic solvents. Electrochim Acta. 2008;53(12):4248-56. http://dx.doi. org/10.1016/j.electacta.2007.12.059.

35. Feng H, Barbosa-Cánovas GV, Weiss J. Ultrasound and food fermentation. USA: Springer; 2016.

36. Del Campo FJ, Coles BA, Marken F, Compton RG, Cordemans E. High-frequency sonoelectrochemical processes: mass transport, thermal and surface effects induced by cavitation in a $500 \mathrm{kHz}$ reactor. Ultrason Sonochem. 1999;6(4):189-97. http://dx.doi. org/10.1016/S1350-4177(99)00017-6.

37. Seymour JD, Gupta RB. Oxidation of aqueous pollutants using ultrasound: salt-induced enhancement. Ind Eng Chem Res. 1997;36(9):3453-7. http://dx.doi.org/10.1021/ie970069o.

38. Wu H, Zhao GL, Mu JW, Li XS, He Y. Effects of ultrasonic dispersion on structure of electrodeposited Ni coating on AZ91D magnesium alloy. Trans Nonferrous Met Soc China. 2010;20:ps703. http://dx.doi.org/10.1016/S1003-6326(10)60566-3.

39. Shao AL, Cheng Y, Zhou Y, Li M, Xi TF, Zheng YF, et al. Electrochemistry properties of multilayer TiN/Ti coatings on NiTi alloy for cardiac occluder application. Surf Coat Tech. 2013;228:S257-61. http://dx.doi.org/10.1016/j.surfcoat.2012.05.129.

40. Bakonyi I, Péter L. Electrodeposited multilayer films with giant magnetoresistance (GMR): progress and problems. Prog Mater Sci. 2010;55(3):107-245. http://dx.doi.org/10.1016/j. pmatsci.2009.07.001

41. Allahyarzadeh MH, Aliofkhazraei M, Rouhaghdam AS, Alimadadi H, Torabinejad V. Mechanical properties and load bearing capability of nanocrystalline nickel-tungsten multilayered coatings. Surf Coat Tech. 2020;386:125472. http://dx.doi. org/10.1016/j.surfcoat.2020.125472.

42. Torabinejad V, Aliofkhazraei M, Rouhaghdam AS, Allahyarzadeh MH. Tribological performance of Ni-Fe-A12O3 multilayer coatings deposited by pulse electrodeposition. Wear. 2017;380381:115-25. http://dx.doi.org/10.1016/j.wear.2017.03.013.

43. Torabinejad V, Aliofkhazraei M, Rouhaghdam AS, Allahyarzadeh $\mathrm{MH}$. Tribological properties of Ni-Fe-Co multilayer coatings fabricated by pulse electrodeposition. Tribol Int. 2017;106:3440. http://dx.doi.org/10.1016/j.triboint.2016.10.025.

44. Torabinejad V, Aliofkhazraei M, Rouhaghdam AS, Allahyarzadeh MH, Kasama T, Alimadadi H. Mechanical properties of multilayer Ni-Fe and Ni-Fe-A12O3 nanocomposite coating. Mater Sci Eng A. 2017;700:448-56. http://dx.doi.org/10.1016/j. msea.2017.06.009.

45. Allahyarzadeh MH, Aliofkhazraei M, Rouhaghdam AS, Torabinejad V, Alimadadi H, Ashrafi A. Electrodeposition mechanism and corrosion behavior of multilayer nanocrystalline nickel-tungsten alloy. Electrochim Acta. 2017;258:883-99. http://dx.doi.org/10.1016/j.electacta.2017.11.139.

46. Gamboa SA, Gonzalez-Rodriguez JG, Valenzuela E, Campillo B, Sebastian PJ, Reyes-Rojas A. Evaluation of the corrosion resistance of $\mathrm{Ni}-\mathrm{Co}-\mathrm{B}$ coatings in simulated PEMFC environment. Electrochim Acta. 2006;51(19):4045-51. http:// dx.doi.org/10.1016/j.electacta.2005.11.021.

47. Yang HY, Guo XW, Chen XB, Birbilis N. A homogenisation pre-treatment for adherent and corrosion-resistant Ni electroplated coatings on Mg-alloy AZ91D. Corros Sci. 2014;79:41-9. http:// dx.doi.org/10.1016/j.corsci.2013.10.024.

48. Nguyen VC, Lee CY, Chen FJ, Lin CS, Liu TY. Study on the internal stress of nickel coating electrodeposited in an electrolyte mixed with supercritical carbon dioxide. Surf Coat Tech. 2012;206(14):3201-7. http://dx.doi.org/10.1016/j. surfcoat.2012.01.005.

49. Hegde AC, Venkatakrishna K, Eliaz N. Electrodeposition of Zn-Ni, Zn-Fe and Zn-Ni-Fe alloys. Surf Coat Tech. 2010;205(7):203141. http://dx.doi.org/10.1016/j.surfcoat.2010.08.102.

50. Mansfeld F, Shih H, Greene H, Tsai CHR. Analysis of EIS data for common. Corrosion processes. American Soc. Test. Mater. 1993;1188:37.

51. Lasia A, Conway BE, BocKris J, White RE. Modern aspects of electrochemistry. New York: Kluwer Academic/Plenum Publishers; 1999.

52. Barsoukov E, Macdonald JR. Impedance spectroscopy, theory, experiment, and applications. New York: Wiley; 2005. http:// dx.doi.org/10.1002/0471716243.

53. Fei JY, Wilcox GD. Electrodeposition of Zn-Co alloys with pulse containing reverse current. Electrochim Acta. 2005;50(13):26938. http://dx.doi.org/10.1016/j.electacta.2004.11.014

54. Elias L, Chitharanjan Hegde A. Electrodeposition of laminar coatings of Ni-W alloy and their corrosion behaviour. Surf Coat Tech. 2015;283:61-9. http://dx.doi.org/10.1016/j. surfcoat.2015.10.025.

55. Chansena A, Sutthiruangwong S. Corrosion behavior of electrodeposited $\mathrm{Co}-\mathrm{Fe}$ alloys in aerated solutions. J Magn Magn Mater. 2017;429:251-6. http://dx.doi.org/10.1016/j. jmmm.2017.01.044.

56. Revie RW, Uhlig HH. Further evidence regarding the dezincification mechanism. Corros Sci. 1972;12(8):669-71. http://dx.doi.org/10.1016/S0010-938X(72)80066-0.

57. Nishimura R. Pitting corrosion of nickel in borate and phosphate solutions. Corrosion. 1987;43(8):486-92. http:// dx.doi.org/10.5006/1.3583891.

58. Okuyama M, Haruyama S. Passive film formed on nickel in a neutral solution. Corros Sci. 1974;14(1):1-14. http://dx.doi. org/10.1016/S0010-938X(74)80003-X.

59. Zhang JQ. Electrochemical measurement technology. Beijing: Chemical Industry Press; 2010.

60. Bellucci F, Nicodemo L, Monetta T, Kloppers MJ, Latanision RM. A study of corrosion initiation on polyimide coatings. Corros Sci. 1992;33(8):1203-26. http://dx.doi.org/10.1016/0010938X(92)90131-L.

61. Hamdy AS, Shoeib MA, Hady H, Abdel Salam OF. Corrosion behavior of electroless Ni-P alloy coatings containing tungsten or nano-scattered alumina composite in $3.5 \% \mathrm{NaCl}$ solution. Surf Coat Tech. 2007;202(1):162-71. http://dx.doi.org/10.1016/j. surfcoat.2007.05.030.

62. Lima-Neto P, Correia AN, Santana RAC, Colares RP, Barros EB, Casciano PNS, et al. Morphological, structural, microhardness and electrochemical characterisations of electrodeposited $\mathrm{Cr}$ and Ni-W coatings. Electrochim Acta. 2010;55(6):2078-86.

63. Sassi W, Dhouibi L, Berçot P, Rezrazi M, Triki E. Comparative study of protective nickel-tungsten deposit behavior obtained by continuous and pulsed currents from citrate-ammonia media. Surf Coat Tech. 2012;206(19-20):4235-41. http://dx.doi. org/10.1016/j.surfcoat.2012.04.030.

64. Young CA, Kellar JJ, Free ML, Drelich J, King RP. Innovations in natural resource processing. In: Jan D. Miller Symposium; 2005; Englewood. Proceedings. Englewood: Society for Mining Metallurgy \& Exploration; 2005.

65. Chiu LH, Wu CH, Chang H. Galvanic corrosion on VacuumBrazed UNS S31803 duplex stainless steel using Ni-Cr-Fe-P alloy filler metals. Corrosion. 2007;63(2):127-34. http://dx.doi. org/10.5006/1.3278337. 